\title{
Los México-americanos en San Antonio, Texas: Análisis de su inserción en autoempleo formal
}

\section{Mexican Americans in San Antonio, Texas: An analysis of their insertion in formal self-employment}

José Luis Manzanares Rivera*

Resumen

Este trabajo analiza la inserción de la población de origen mexicano en el mercado laboral en San Antonio, Texas; en particular, responde a la interrogante sobre los determinantes del empleo en empresas propias formalmente registradas. La metodología analiza microdatos de la encuesta americana de comunidades (ACS, por sus siglas en inglés) mediante la herramienta estadística de estimación logística. Los principales resultados indican que atributos como el dominio del idioma inglés o el origen de la persona podrían contribuir al entendimiento de la inserción en el mercado laboral de la población de origen mexicano que vive en Estados Unidos y no necesariamente constituyen barreras para la inserción en el mercado laboral bajo la categoría de autoempleo en ciudades de migración tradicional como San Antonio, Texas.

Palabras clave: empleo, geografía humana, mexicanos en Estados Unidos.

Recibido: 25 de junio de 2013.

Aceptado: 19 de septiembre de 2014.

\begin{abstract}
This paper analyzes the insertion of the Mexican population in the job market in San Antonio, Texas. In particular, it responds to the question of what determines employment in individual, formally incorporated businesses. The methodology analyzes microdata from the American Community Survey (acs) using a logistic statistical estimation tool. The main results indicate that attributes such as command of the English language or an individual's origin could contribute to an understanding of job market insertion for the Mexican population living in the U.S. and do not necessarily constitute barriers for labor market insertion in the self-employment category in cities with traditional migration such as San Antonio, Texas.

Keywords: employment, human geography, Mexicans in USA.
\end{abstract}

* El Colegio de la Frontera Norte. Dirección: Progreso 503, C.P. 26020, Piedras Negras, Coahuila. Correo electrónico: jlmanzanares@colef.mx 
José Luis Manzanares Rivera / Los México-americanos en San Antonio, Texas

\section{Introducción}

De manera predominante, los estudios que abordan la inserción en el mercado laboral de la población de origen mexicano en Estados Unidos, en las últimas décadas, han enfatizado las adversidades que enfrenta este grupo poblacional vinculadas a los niveles relativamente bajos de capital humano medidos por educación o el incipiente dominio del idioma inglés (Chiswick, 1990; Donato y Massey, 1993; Donato y Blake, 2012).

Se reconoce que la formación de redes sociales que ocurre de una generación a otra o el incremento de habilidades asociadas al capital humano, como un mayor dominio del idioma inglés, encuentran su expresión en cambios favorables en la participación de esta población en el mercado laboral (Grogger y Trejo, 2002, p. 79).

Ante este escenario, el estudio de formas de inserción laboral como el autoempleo, ha cobrado interés. Para autores como Ramírez y Hondagneu-Sotelo (2009), el autoempleo en la modalidad informal, es una expresión de la capacidad empresarial y habilidad emprendedora como respuesta a las barreras que encuentran las minorías para ingresar en el mercado formal (Ramírez y Hondagneu-Sotelo, 2009, p. 74).

Mientras que en un contexto de asimilación intergeneracional, estudios como el de Valdez (2006) perciben el autoempleo como un indicador que más que contribuir a la movilidad económica, previene de un proceso de asimilación negativo (hacia mayor pobreza), lo que es especialmente aplicable a aquellos trabajadores de origen mexicano con bajos niveles de capital humano (Valdez, 2006, p. 418).

Mas aún, el estudio del autoempleo en su modalidad formal es un rasgo de la experiencia migratoria que genera atención académica y que ha sido escasamente documentado mediante información censal oficial, lo cual podría ser importante para aportar elementos complementarios que permitan el entendimiento de esta práctica.

El presente trabajo tiene como objetivo contribuir al análisis del fenómeno del autoempleo formal y actividad profesional por cuenta propia (en adelante referido como autoempleo) en un entorno geográfico de presencia tradicional de inmigrantes de origen mexicano, como lo es el condado Bexar, en el que se localiza la ciudad de San Antonio, Texas. 
Estos espacios conocidos como traditional Gateway cities (Massey, Jacob, Rugh y Pren, 2010), son relevantes para el análisis por la intensidad de la interacción entre individuos de origen común, lo que en términos teóricos y siguiendo a Granovetter (1973), puede incidir en los resultados que grupos poblacionales específicos, que comparten valores, obtienen en el entorno laboral.

La hipótesis que se busca probar asume que variables como el dominio del idioma inglés o el origen mexicano de la persona en ciudades de migración tradicional como San Antonio, Texas, no necesariamente implican barreras significativas para la inserción de la población de origen mexicano en el mercado laboral formal dentro de la categoría de autoempleo.

A pesar de que se han realizados numerosos esfuerzos previos en el tema de autoempleo entre población de origen mexicano en Estados Unidos, se observa en esta literatura una tendencia a sobrerrepresentar los casos de ciudades como Chicago (Raijman y Tienda, 1999; Raijman, 2001) o Los Ángeles (Barros, 2007; Ramírez y Hondagneu-Sotelo, 2009).

Estas contribuciones dan cuenta de la importancia del tema, siendo una de sus características comunes la aplicación de un enfoque cualitativo. Por otro lado, otros estudios notables pero que aplican un enfoque cuantitativo, pierden de vista las especificidades de espacios como las ciudades, al considerar amplias regiones como el suroeste de Estados Unidos agregando los estados de Arizona, California, Colorado, New Mexico y Texas en un solo grupo de estudio (Valdez, 2006, p. 402), dejando de lado el contexto histórico de estos espacios. No obstante, es reconocido que hay amplias diferencias en la forma en que la población de origen mexicano interactúa en espacios tan diferentes como lo son las ciudades en los estados de California o Texas (Arreola, 1987).

En el presente trabajo se argumenta que la disponibilidad creciente de información censal desagregada sobre la población de origen mexicano en aquel país es una fuente que podría aportar datos complementarios sobre el tema, por lo que la estrategia metodológica que se propone se basa en el análisis de microdatos de uso público, Public Use Microdata (Pum) de la encuesta americana de comunidades en la versión multianual 2008-2010 (U. S. Census Bureau. American Community Survey [ACs], 2012). Éste es un proyecto censal que contiene información demográfica y socioeconómica a nivel hogar y personal con representatividad geográfica desagregada. 
Asimismo, se analiza el autoempleo en el mercado formal mediante la herramienta de regresión logística.

Respecto de la selección de San Antonio como ciudad de estudio, se considera el hecho de que su estructura demográfica es más homogénea desde una perspectiva étnica, que otras grandes ciudades en la categoría de destinos tradicionales tales como Nueva York, Chicago o Los Ángeles ${ }^{1}$ (U.S. Census Bureau, 2012). Lo que será útil para estudiar el autoempleo desde una perspectiva intragrupo en un espacio con un contexto histórico y cultural único en Estados Unidos. Al respecto, esta ciudad es considerada por algunos autores como la capital cultural de la población Méxicoamericana, en Estados Unidos (Arreola, 1987).

El artículo se organiza en cinco secciones. La sección dos hace una revisión de los estudios previos; en la sección tres, se presenta un contraste del mercado laboral para la población de origen mexicano a escala estatal y para el condado Bexar, condado en el que se localiza la ciudad de San Antonio; la sección cuatro analiza el autoempleo en el mercado formal mediante la herramienta de regresión logística; y en la sección cinco, se presenta una reflexión sobre las implicaciones de los resultados.

\section{Investigaciones previas}

La teoría de enclaves étnicos económicos ha sido por décadas un punto de partida para comprender la dinámica de las relaciones sociales y, en particular, la participación laboral entre personas de origen común en un entorno migratorio; notablemente, la corriente analítica basada en los trabajos pioneros de Portes (1981), ha investigado el papel de los nexos de origen de las personas que laboran en diversas ciudades para el caso de Estados Unidos, si bien se tiene una sobrerrepresentación empírica en estudios para minorías de origen cubano o los chinos. Sin embargo, esta postura teórica alude a la interacción de minorías en un contexto acotado, en términos de Portes:

${ }^{1}$ Si bien la ciudad de Los Ángeles tiene un número mayor de personas de origen mexicano y población hispana en general, en términos proporcionales, la ciudad de San Antonio tiene una concentración relativa más elevada con $63 \%$ de población hispana contra $48.4 \%$ en Los Ángeles. De esa proporción de hispanos en San Antonio, 91.3\% es de origen mexicano. 
"Enclaves consist of immigrant groups which concentrate in a distinct spatial location and organize a variety of enterprises serving their own ethnic market and/or the general population" (1981, pp. 290-291).

Esta base teórica incluye los trabajos empíricos sobre población de origen mexicano de autores como Barros (2007), quien analiza la formación de pequeñas empresas en la ciudad de Los Ángeles introduciendo el tema del matrimonio como elemento central en la configuración de redes sociales entre población de origen mexicano y salvadoreño; y el trabajo de Ramírez y Hondagneu-Sotelo (2009), que estudia el autoempleo en actividades de jardinería en California. Un rasgo distintivo de este último trabajo es su propuesta conceptual sobre las formas "híbridas de autoempleo", que incorporan grados de formalidad mixtos y el papel que estas ocupaciones tienen como un elemento de movilidad ocupacional y social entre la población de origen mexicano.

Siguiendo la distinción teórica planteada por Light, Sabagh, Bozorgmehr y Der-Martirosian (1994) sobre el concepto de economía étnica y enclaves étnicos, se considera que este trabajo se enmarca en la teoría de economía étnica, pero no en el caso particular sobre enclaves étnicos. Si bien se reconoce la importancia de la aproximación teórica sobre enclaves económicos étnicos, este marco teórico podría no ser adecuado para el caso de la población de origen mexicano en San Antonio, ya que este grupo poblacional, con vínculos históricos y culturales con predominio de las raíces hispanas, no es precisamente una minoría. Da cuenta de $91.3 \%$ de la población hispana en la ciudad, según los datos más recientes del censo estadounidense (U. S. Census Bureau, 2010), su actividad económica es diversificada y se extiende en términos espaciales a lo largo de la ciudad, por lo que se tiene un entorno social no compatible con el análisis de los enclaves económicos étnicos.

Por otro lado, para comprender el papel que tiene el autoempleo para grupos poblacionales específicos en Estados Unidos, la vertiente teórica sobre asimilación y movilidad social permite tener elementos adicionales. Esta vertiente se utilizó predominantemente durante la década de los setenta para analizar las minorías de origen asiático, siendo el trabajo de Light (1972), un ejemplo clásico de este enfoque. En los planteamientos de este autor, se observan dos elementos destacados retomados en las décadas siguientes en aplicaciones empíricas sobre autoempleo entre la 
población de origen mexicano: el primero, se refiere al autoempleo como una alternativa ante las barreras del mercado laboral para los recién llegados, y el segundo, como un medio de movilidad social.

Dentro de las barreras sugeridas en esta línea aplicada a los mexicanos para el caso de Chicago, Rajman (2001) refiere al lenguaje: "Probably the main handicap faced by immigrants in the host labor market is the lack of English proficiency, which affects transferability of skills from the home country to the host society thus reducing their chances of getting suitable jobs" (2001, p. 395).

Sin embargo, como se argumenta en esta investigación, este atributo podría funcionar de forma distinta en un entorno más homogéneo en cuanto a su composición étnica, como lo es la ciudad de San Antonio, Texas.

Un segundo elemento central de la teoría de asimilación que ha presentado debate es el referente a la relación entre autoempleo y niveles de ingreso. En el terreno empírico el trabajo de Lofsrom (2002), ${ }^{2}$ aplicando un enfoque cuantitativo, encuentra que los ingresos de la población migrante que labora en autoempleo tienden a converger con las percepciones de los trabajadores blancos no hispanos que perciben tanto sueldos y salarios como aquellos que laboran en autoempleo (Lofstrom, 2002, p. 86).

Un caso particular de la teoría de la asimilación se observa en la aplicación que hace Valdez (2006), quien destaca la existencia de una asimilación por segmentos diferenciados según el nivel de capital humano, el género y el lugar de nacimiento, ya sea población nacida en México o de origen mexicano nacida en Estados Unidos; este caso es revelador independientemente del problema de agregación regional mencionado en la introducción, porque al vincular los ingresos a esta forma de inserción en el entorno laboral, pone de relieve las funciones distintas que tiene el autoempleo frente a la movilidad social de los mexicanos en Estados Unidos.

La tercera corriente teórica que permite contar con elementos para el desarrollo de este trabajo es el emprendimiento, que se define, siguiendo la noción clásica de Schumpeter, como la creación de nuevas oportunidades a partir de recursos previamente desconectados.

${ }^{2}$ El autor analiza en un artículo posterior en Lofstrom (2006), la relación de la entrada al empleo por cuenta propia por parte de la población México-americana, su trabajo es un antecedente importante para el análisis del emprendimiento para este segmento poblacional. 
En un contexto más amplio, Granovetter (2005), en su trabajo sobre el impacto de la estructura social en los resultados económicos, se refiere a las redes sociales como el mecanismo que permite conectar los recursos y las ideas de redes separadas, posibilitando entre otros elementos, el proceso de emprendimiento (2005, p. 46), siendo un caso especial de este proceso, la modalidad de autoempleo.

Si bien diversos estudios han mostrado que la población mexicana se caracteriza por ser altamente emprendedora (Fairlie y Woodruff, 2004), cuando se analiza a la población de origen mexicano en el contexto migratorio, en Estados Unidos, los niveles observados de autoempleo no sólo son considerablemente inferiores a los observados en México, sino que son notablemente inferiores a otros grupos étnicos, como la población asiática o aquella proveniente de Cuba (Robles y Cordero-Guzmán, 2007, p. 28).

Esta regularidad empírica ha llevado a algunos autores a sugerir que el autoempleo entre los mexicanos en Estados Unidos, más que ser un reflejo de su actitud emprendedora, es una alternativa laboral que cumple otra función: la de una figura temporal para transitar hacia otros esquemas como el empleo asalariado (Georgarakos y Tatsiramos, 2009, p. 169).

En este mismo sentido, Toussaint-Cameou (2008), utilizando información a nivel de áreas metropolitanas, muestra que la población de origen mexicano tiene una tendencia a presentar elevados niveles de autoempleo en ciudades donde hay una proporción amplia de este grupo poblacional, evidencia que, por un lado, permite destacar las ventajas de un análisis con una desagregación geográfica mayor y, por otro, podría reforzar la hipótesis sobre el papel de las redes sociales.

\section{Análisis exploratorio}

La ciudad de San Antonio se localiza en el condado Bexar, tiene una población según los estimados del censo estadounidense a 2011 de 1756153 personas, es la séptima ciudad más grande en Estados Unidos y la segunda en el estado de Texas (después de Houston); de esta población, $77.4 \%$ es de origen hispano. El condado Bexar es además el centro de un área metropolitana más amplia que incluye ocho condados periféricos que mantienen una relación funcional con el condado central asociada a la 
dinámica del mercado laboral en la ciudad de San Antonio. La población de origen mexicano en el condado se concentra en la parte sur y centro del mismo donde su participación llega a niveles de hasta $93.9 \%$ del total, como se muestra en la figura 1.

Sin embargo, las zonas de la ciudad que presentan un nivel de ingreso personal promedio más elevado, se localizan en el lado opuesto (al norte de la ciudad), con ingresos que alcanzan los 51912.95 dólares (figura 2). Es precisamente en esta zona norte donde los flujos más recientes de migración de mexicanos provenientes de ciudades como Monterrey se han asentado, (el área conocida como Sonterra es emblemática de este nuevo proceso migratorio). Mientras el ingreso personal promedio en el área con mayor presencia de población de origen mexicano (en el centro y sur del condado), es de sólo 22327.99 dólares anuales (inferior en 57\%).

\section{Capital humano}

En términos teóricos se ha demostrado notablemente por la corriente de análisis de capital humano impulsada por Becker (1975), Mincer (1974)

Figura 1. Población de origen mexicano, Bexar County, Texas

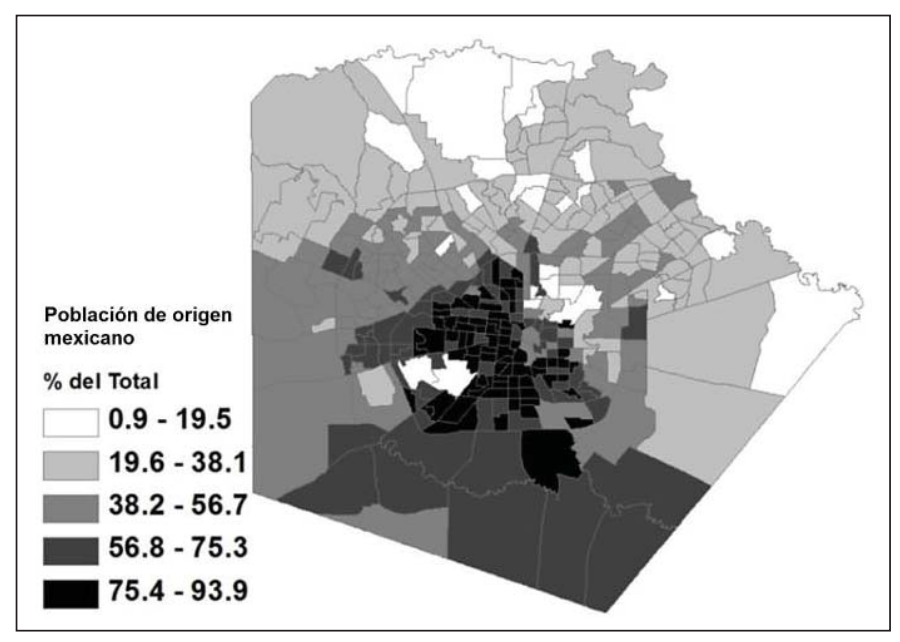

Fuente: Elaboración propia con datos de U.S. Census Bureau 2010. Tiger Line Shapes y ACS. 
Figura 2. Niveles de ingreso personal promedio

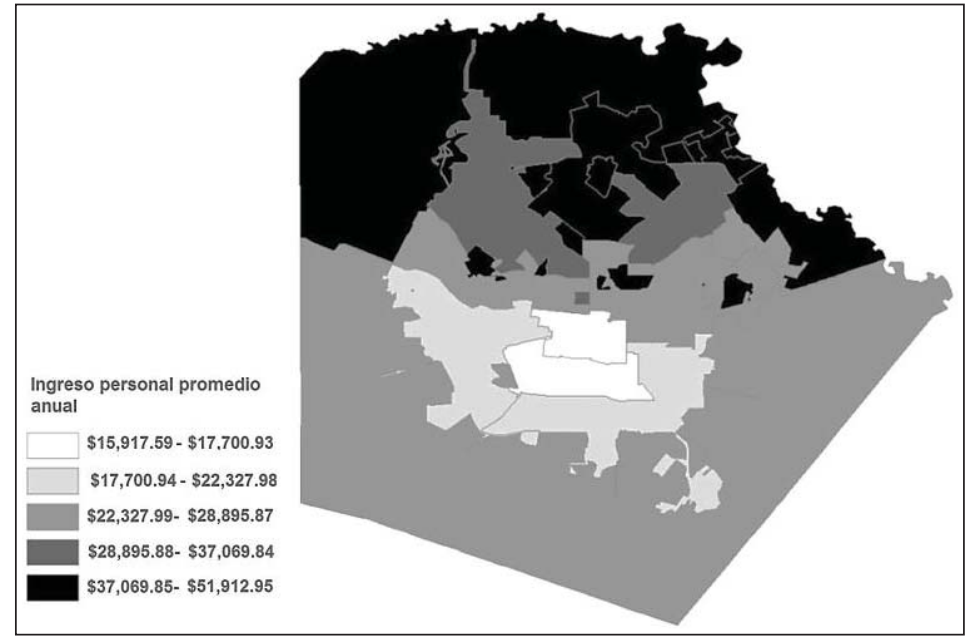

Fuente: Elaboración propia con datos de U.S. Census Bureau 2010. Tiger Line Shapes y ACS.

y otros, que hay una relación estrecha entre los niveles de escolaridad y las remuneraciones de ingreso que perciben los individuos; Becker subraya: "If education were economically important, I reasoned, money rates of return on education ought to be significant" (1975, p. 1).

Mincer por su parte apunta que: "The positive relation between an individual's schooling and his subsequent earnings may be understood to reflect productivity augmenting effects of education" (1974, p.1). En el terreno empírico en el contexto de los mercados laborales a los que se enfrentan los migrantes, diversos estudios corroboran esta relación no sólo en el caso de Estados Unidos y la migración de mexicanos, sino también en países con una dinámica migratoria intensa como Australia (Mahuteau y Junankar, 2007, p. 17) o Canadá (Xue, 2008, p. 23).

Para efectos de esta investigación, resulta de interés determinar cómo se relacionan estas variables en un entorno de emprendimiento, es decir, cómo se comportan los ingresos a medida que el individuo tiene niveles más altos de calificación, en un entorno en donde el empleo del individuo se da a partir de la creación de una empresa propia registrada formalmente; en comparación con aquellos individuos que siguen una trayectoria "tradicional" al emplearse en una empresa ya sea privada o del sector 
público. Más aún, ¿̇ómo se da esta interacción en un contexto laboral como el que enfrentan los trabajadores de origen mexicano en Gateway cities del estado de Texas?

Una primera aproximación a esta relación se observa en la figura 3, que presenta el comportamiento de los ingresos personales promedio en el periodo 2008-2010 para distintos niveles educativos, la figura se centra únicamente en aquellos trabajadores de origen mexicano, en el condado Bexar.

La primera característica destacada, es que los emprendedores perciben mayores ingresos promedio que los trabajadores "tradicionales" para cada nivel educativo, ${ }^{3}$ esta brecha en el ingreso, inicialmente es de más del doble a favor de los emprendedores, tendencia que permanece hasta que alcanza su punto máximo con aquellos trabajadores que tienen el grado de maestría, a este nivel el ingreso promedio de los emprendedores es de

Figura 3. Ingreso anual personal promedio emprendedores y no emprendedores. Población de origen mexicano, Bexar, County, Texas

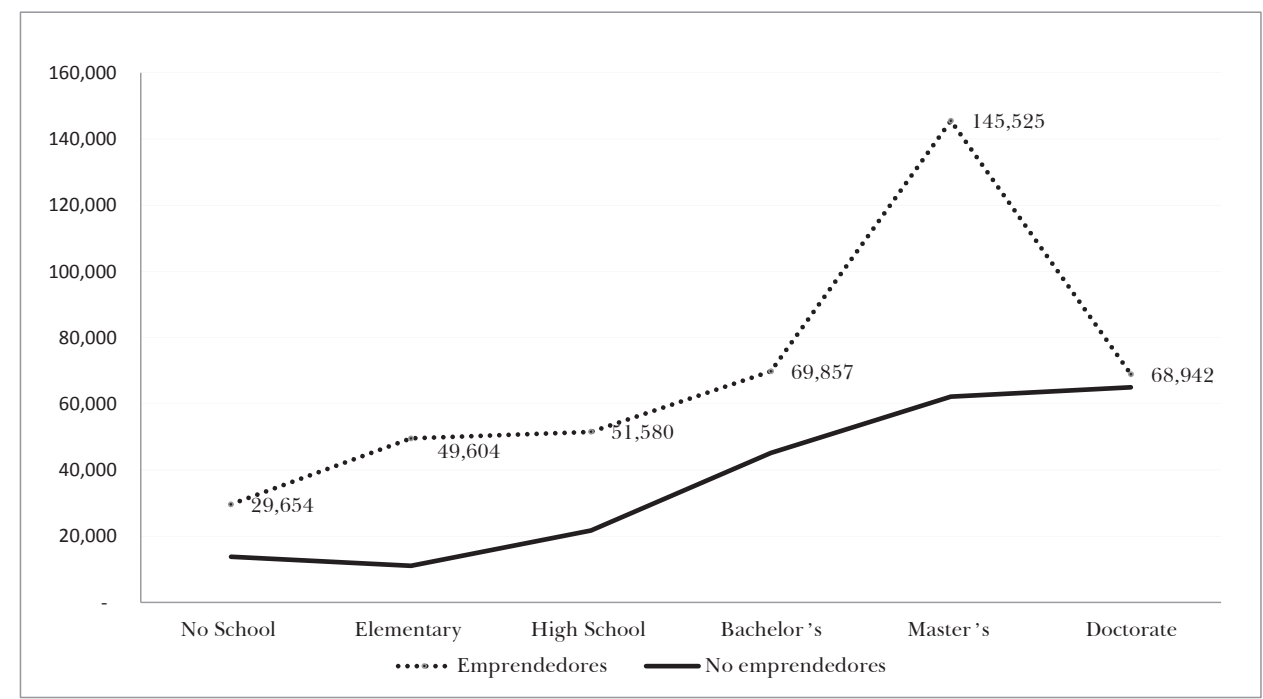

Nota: Ingreso expresado en dólares a precios constantes de 2010.

Fuente: Elaboración propia con base en microdatos de Acs Multiyear Sample 2008-2010.

${ }^{3}$ A excepción únicamente del nivel doctorado en donde la diferencia es marginal entre ambos. 
145524.9 dólares contra 62206.98 para aquellos trabajadores que siguen una trayectoria tradicional de empleo.

En segundo lugar, es interesante notar la contribución que cada nivel educativo genera al ingreso percibido; así, la mayor contribución para los trabajadores tradicionales se presenta al pasar del nivel de preparatoria al profesional, en este grupo un trabajador que logra obtener un título universitario percibe un incremento de $48.23 \%$ respecto de aquellos que logran un nivel de preparatoria.

La contribución más notable para los emprendedores se presenta al pasar de la licenciatura a la maestría con una magnitud comparable a la de los trabajadores tradicionales (48\%); sin embargo, para los emprendedores, el perseguir niveles educativos superiores a maestría, aparentemente no resulta una decisión racional ya que en promedio se observa una caída drástica en su nivel de ingreso de 145000 a 69000 dólares anuales; por su parte el paso de maestría a doctorado por un individuo con una trayectoria tradicional es de hecho rentable, si bien el beneficio en términos de ingreso es marginal (sólo 6734.21 dólares adicionales).

A continuación se explora el nivel de dominio del idioma inglés bajo la premisa de que en un contexto de migración, el dominio del lenguaje del país receptor es un atributo de capital humano que influye en diversos aspectos del mercado laboral, como el tipo de ocupación y los niveles de ingreso de los individuos, e incluso algunos autores asocian esta variable con los tiempos de traslado al sitio de trabajo.

Como lo documentan los trabajos pioneros de Chiswick (1990), desde la década de los noventa, los efectos de esta variable sobre los niveles de ingreso personal. Si bien Rumbaut (2006), usando microdatos de uso público para del censo del año 2000, encuentra que hay un proceso de asimilación intergeneracional, en el que el dominio en el idioma inglés de la población de origen mexicano en Estados Unidos mejora notablemente al pasar de $6.3 \%$ a $34.5 \%$ entre las personas de la primera generación (nacidos fuera de E.U.A.) y la segunda, respectivamente (nacidos en E.U.A). Este proceso de asimilación es importante porque potencialmente podría influir en el tipo de empleo al que los trabajadores con mayor arraigo ${ }^{5}$

\footnotetext{
${ }^{4}$ Para la población entrevistada de cinco años y más.

${ }^{5}$ Como el caso de aquellos que viven en el área de San Antonio, Texas, y otras ciudades en la categoría de "Gateway destinations".
} 
pueden acceder y adicionalmente determinar las condiciones de ingreso de las subsecuentes generaciones.

Para los microdatos analizados en el condado de Bexar, Texas, en el periodo 2008-2010, se observa una clara diferencia en el dominio del idioma entre las personas de origen mexicano de segunda y primera generación (nacidas dentro y fuera de Estados Unidos respectivamente), con $80.4 \%$ de la población que lo habla muy bien en el primer caso, y $32.9 \%$ en el segundo caso. Este comportamiento es interesante porque la proporción que lo habla muy bien es comparable con el fenómeno de asimilación reportado por Rumbaut (2006); la proporción de 32.9\% que habla inglés muy bien entre los individuos nacidos en México (primera generación) que viven en el área de San Antonio, es comparable con la proporción a nivel nacional para la segunda generación, lo que podría ser un indicador de la existencia de un intensivo proceso de asimilación en el área de San Antonio. Los resultados para la población en el condado de Bexar están presentados en el cuadro 1, donde se encuentran desagregados por lugar de nacimiento y grado de habilidad en el idioma inglés para la población de origen mexicano.

El comportamiento que se exhibe por los datos del cuadro 1 de forma implícita nos permite destacar, tal como advierten Duncan, Holtz y Trejo (2006), que el nivel de dominio del idioma inglés no sólo es una función del tiempo que la persona lleva viviendo en el país receptor, sino que se determina además por variables como el nivel educativo del individuo. ${ }^{6}$

Adicionalmente, el nivel de dominio del idioma inglés se asocia con otras especificidades en el mercado laboral, como el tiempo de traslado al trabajo (commute times); diversas investigaciones en la literatura sobre migración han estudiado esta relación para intentar demostrar si hay lo que se denomina spatial mismatch of racial minorities (Preston y Mclafferti, 1999), encontrando mayores tiempos de traslado para los grupos migrantes vis a vis la población nativa (Cuesta, Verduras y Carcedo, 2008).

${ }^{6}$ Éste podría ser un factor que explica el elevado nivel de dominio entre las personas de origen mexicano de primera generación en San Antonio, ya que como se indicó en la revisión empírica, los flujos de migración que llegan a San Antonio han estado influenciados en la última década por una corriente regional con gran presencia de población proveniente de ciudades como Monterrey. 


\section{Cuadro 1. Nivel de dominio en el idioma inglés en el condado Bexar, Texas, de personas de origen mexicano nacidas fuera y dentro de Estados Unidos}

\begin{tabular}{|ccc|}
\hline Dominio idioma inglés & Estados Unidos (\%) & El exterior (\%) \\
\hline Muy bien & 80.42 & 32.9 \\
Bien & 13.99 & 23.9 \\
No bien & 4.82 & 27.3 \\
Para nada & 0.77 & 15.9 \\
\hline
\end{tabular}

Fuente: Elaboración propia con base en microdatos de uso público. ACS U.S. Census Bureau, 2008-2010.

\section{Perfil laboral}

Una vez realizada la exploración de los efectos de la educación en los niveles de ingreso, la siguiente interrogante es determinar en qué ocupaciones se emplean predominantemente los emprendedores y cuál es su rentabilidad de acuerdo con el grado de capital humano que estas ocupaciones demandan. Adicionalmente, se busca determinar si hay diferencias significativas tanto desde la perspectiva del nivel de ingreso como en los requerimientos de capital humano, respecto del tipo de empleos que generalmente eligen aquellos individuos que deciden ser empleados en la connotación tradicional.

Para lograr lo anterior, se explora a continuación el perfil ocupacional de los emprendedores de acuerdo con la actividad económica en la que opera su empresa, según la codificación del Sistema de Clasificación Industrial de América del Norte (NAICS, por sus siglas en inglés). La figura 4 muestra las 10 principales actividades económicas en las que incursionan los emprendedores de origen mexicano en el área de San Antonio.

Como se observa, el perfil ocupacional de los emprendedores no se caracteriza por actividades que incorporen capital humano de nivel universitario, ${ }^{7}$ prácticamente uno de cada dos emprendedores realiza actividades vinculadas a la industria de la construcción; en segundo lugar, se ubican aquellos que realizan actividades de servicios automotrices (17\%

${ }^{7}$ Con la excepción de tres categorías: 6211 médicos, 531 bienes raíces, y 5415 diseño de sistemas computacionales y servicios relacionados. 


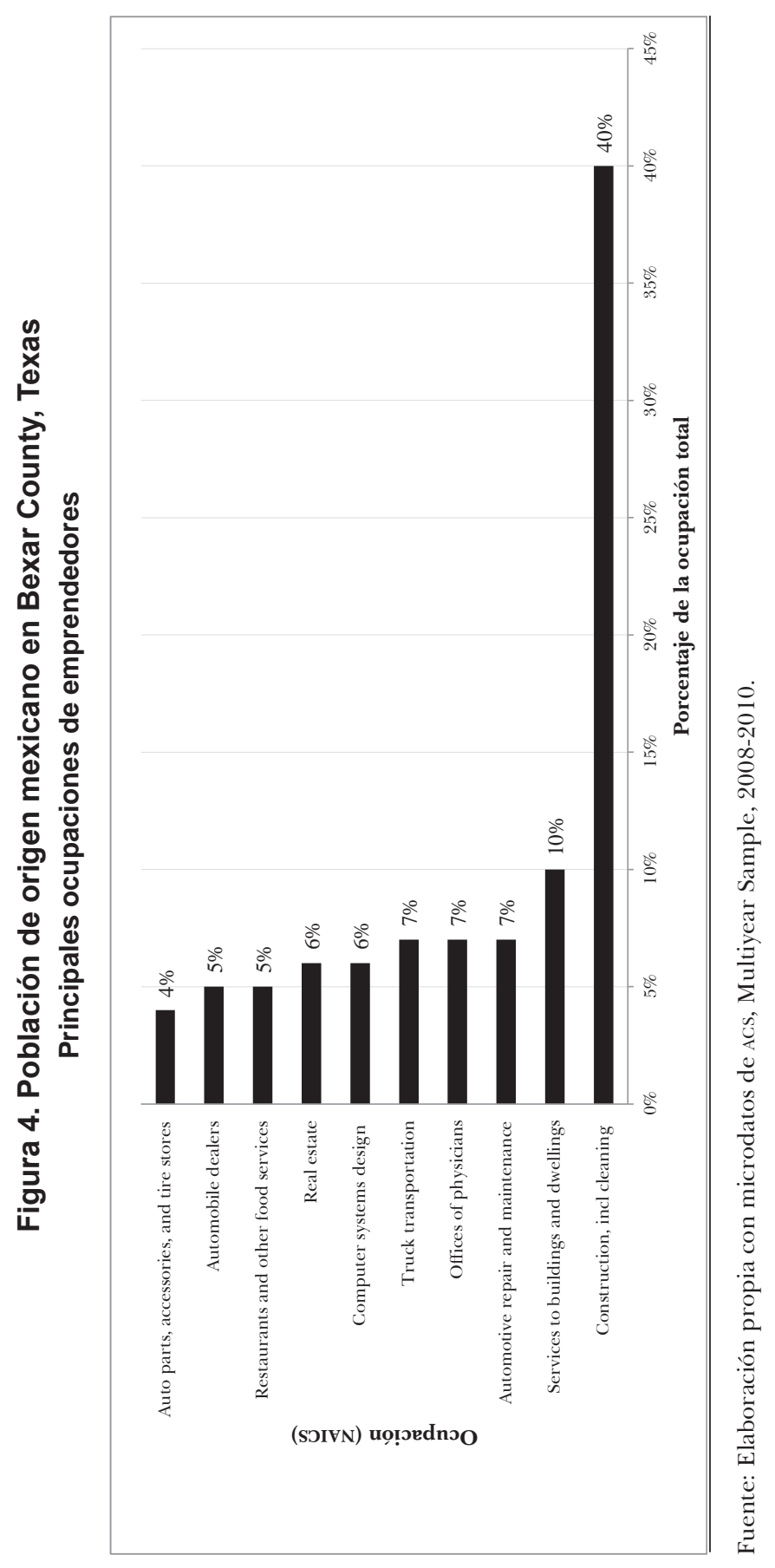


del total), desde lotes de carros hasta negocios de reparación de llantas y talleres mecánicos; este perfil en la creación de empresas, corresponde a un mercado laboral intensivo en mano de obra no calificada, característica que resulta una ventaja para la inserción de aquellos migrantes de primera generación o aquellos que mantienen un estatus de residencia no legal, quienes se ven favorecidos por la afinidad cultural y el lenguaje como medios de acceso a este mercado.

Ahora bien, para explorar el comportamiento de los ingresos percibidos en las principales actividades económicas en las que participan los emprendedores, se presenta la figura 5, que indica el ingreso para las 10 principales actividades económicas de los emprendedores de origen mexicano en el condado de Bexar; la figura permite contrastar dos elementos: el primero es la rentabilidad vinculada al contenido del capital humano ya que tal como se mostró en la sección sobre el efecto del capital humano sobre los ingresos, se espera una relación positiva entre el grado de escolaridad y el ingreso percibido, de tal manera que ocupaciones que requieren mayor nivel de calificación, teóricamente permitirían un ingreso promedio más elevado que aquellas intensivas en mano de obra no calificada. Por otra parte, la figura permite verificar si las ocupaciones más recurrentes para los emprendedores son las más rentables o, por el contrario, predomina como determinante del nivel de ingresos el factor de capital humano que la actividad en cuestión incorpora.

Observamos también que las actividades económicas más rentables dentro del conjunto de las 10 más recurrentes entre los emprendedores de origen mexicano son: el diseño de sistemas computacionales, los servicios médicos y empresas de bienes raíces. Estas actividades son sin lugar a dudas las actividades que demandan una mano de obra de mayor calificación dentro de las 10 principales actividades, por lo que es evidente que el factor de capital humano es clave para explicar la rentabilidad. Las tres actividades más rentables registran ingresos personales superiores al ingreso promedio anual que es de 43901 dólares para este conjunto de ocupaciones económicas más recurrentes, llegando a 82975 y 80430 dólares en los casos de diseño de sistemas computacionales y servicios médicos, respectivamente.

Esta caracterización implica también que los emprendedores de origen mexicano en San Antonio, concentran sus esfuerzos de emprendimiento en actividades no rentables vinculadas al uso intensivo de mano de obra 


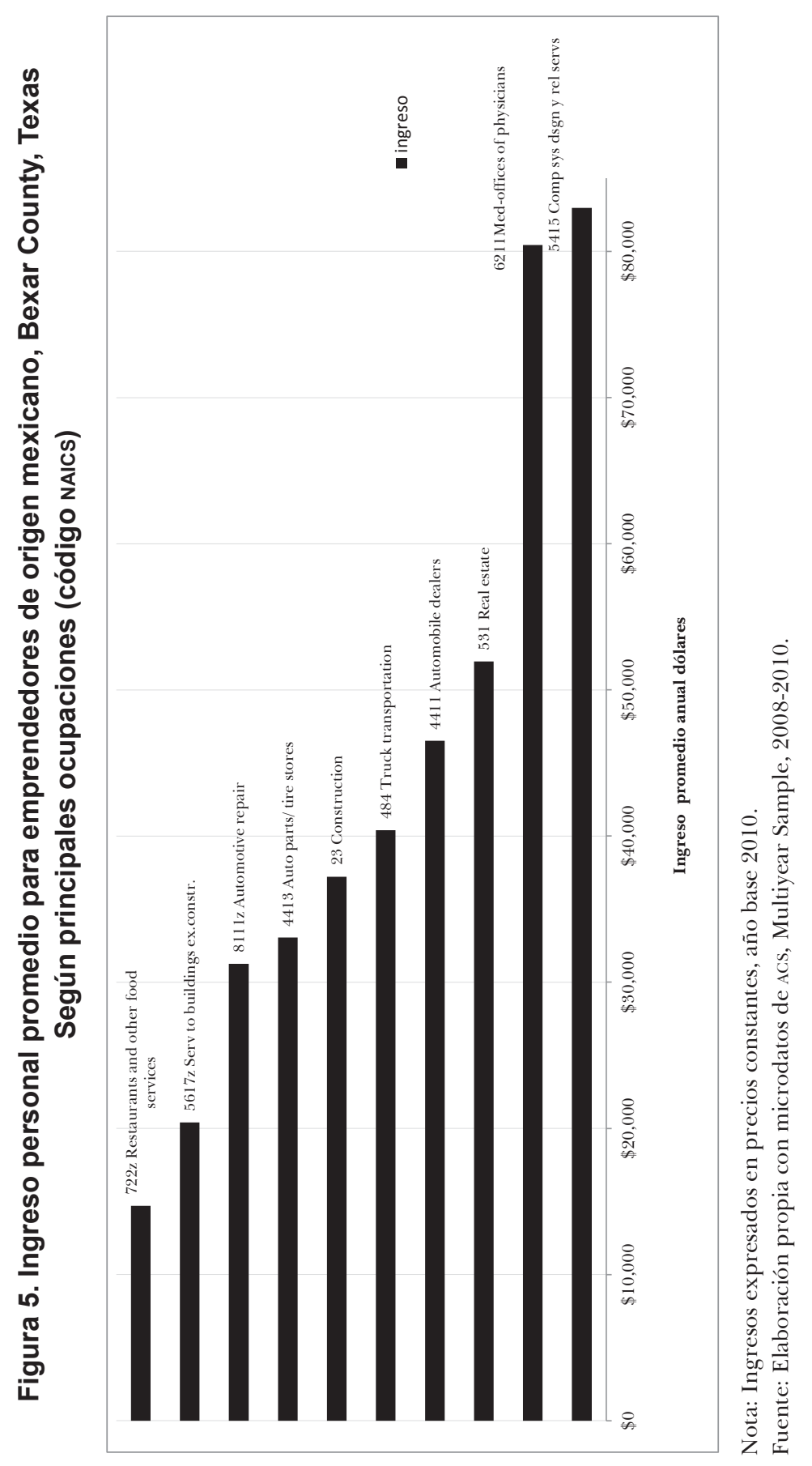


no calificada como los servicios de construcción, negocios de trasporte de carga, talleres mecánicos o restaurantes.

El segundo punto de este contraste se hace respecto del perfil ocupacional de aquellos individuos que deciden seguir una trayectoria tradicional como empleados; el criterio de contraste se presenta sobre el tipo de ocupaciones según el grado de capital humano que requieren y en segundo lugar en la rentabilidad. Para lograr lo anterior, se estimaron las 10 principales ocupaciones para este grupo de trabajadores de origen mexicano en el condado de Bexar y posteriormente se describió la rentabilidad de estas ocupaciones, medida a través del nivel de ingresos. La figura 6 reporta las 10 principales ocupaciones para los no emprendedores según el NAICS.

Es evidente, en primera instancia, que las ocupaciones predominantes para los no emprendedores requieren un contenido de capital humano mayor que aquellas en las que laboran los emprendedores. La lista de este grupo incluye trabajos en hospitales, agentes de seguros, instituciones educativas tanto de nivel básico y medio superior como de nivel superior, actividades bancarias, entre otras.

Un perfil laboral como el descrito, se caracteriza por incorporar mano de obra calificada, por lo que el contraste respecto del perfil ocupacional de los emprendedores es evidente; en el último caso no se observa evidencia de altos requerimientos de capital humano, mientras en el presente caso es muy evidente. A pesar de esta característica, la rentabilidad promedio es menor para los no emprendedores (35 778 dólares frente a 43901 en empleo por cuenta propia).

En la figura 7 se reporta el ingreso promedio para estas 10 principales ocupaciones del grupo de trabajadores tradicionales. Nuevamente, destaca el hecho de que ocupaciones de mayor requerimiento de capital humano se asocian con los rendimientos más altos, mientras las ocupaciones intensivas en mano de obra no calificada reciben ingresos personales por debajo de la media del grupo; así, aquellos individuos de origen mexicano que laboran como empleados en restaurantes, en lotes de carros, tiendas departamentales o son artistas independientes (grupos norteños, por ejemplo), perciben ingresos menores a 35778.02 dólares por año, mientras que los que laboran en aseguradoras, actividades bancarias, hospitales o universidades superan los 40000 dólares por año, siendo las ocupaciones en aseguradoras las más rentables, con 56489.46 dólares para este grupo. 


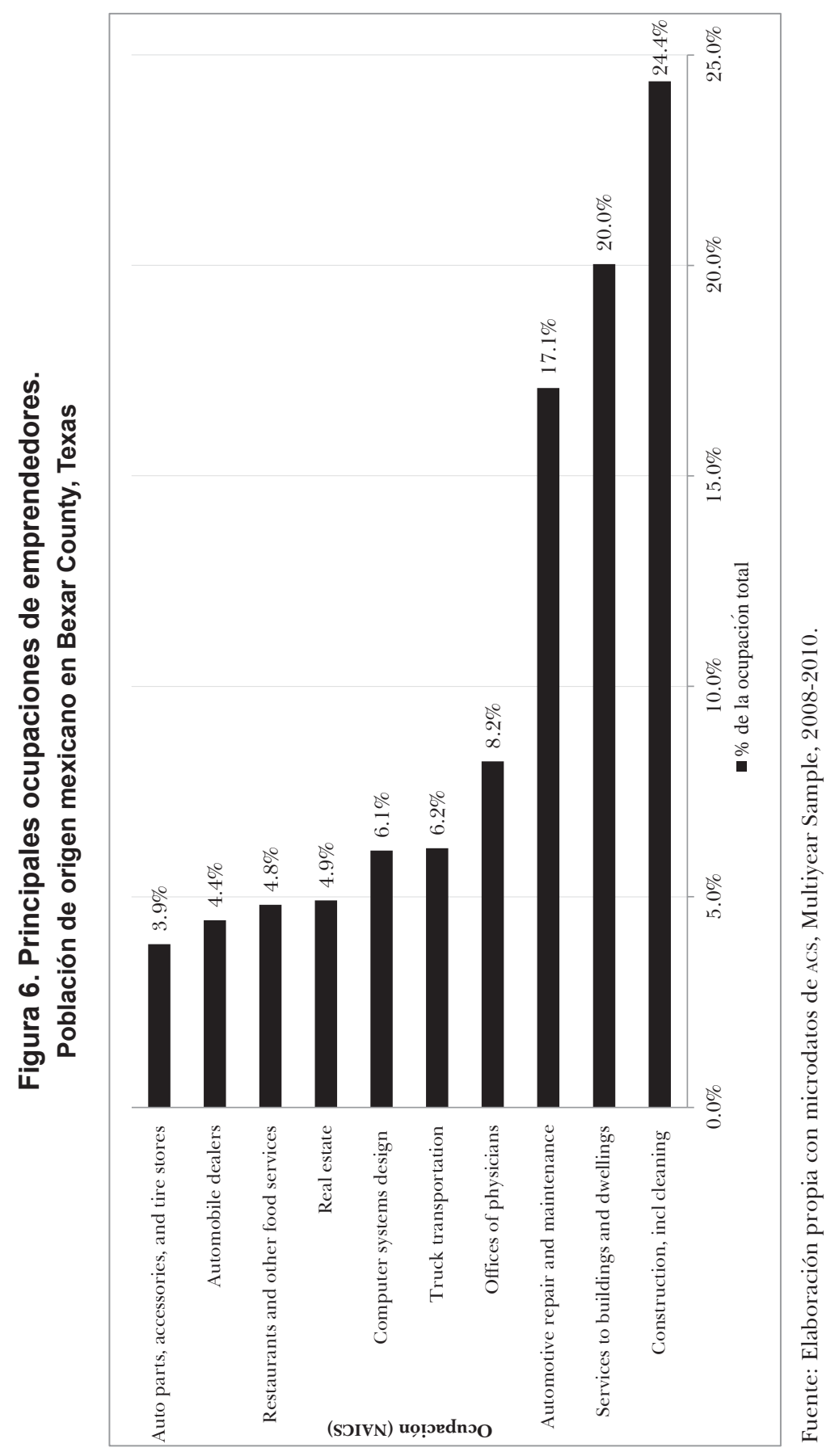




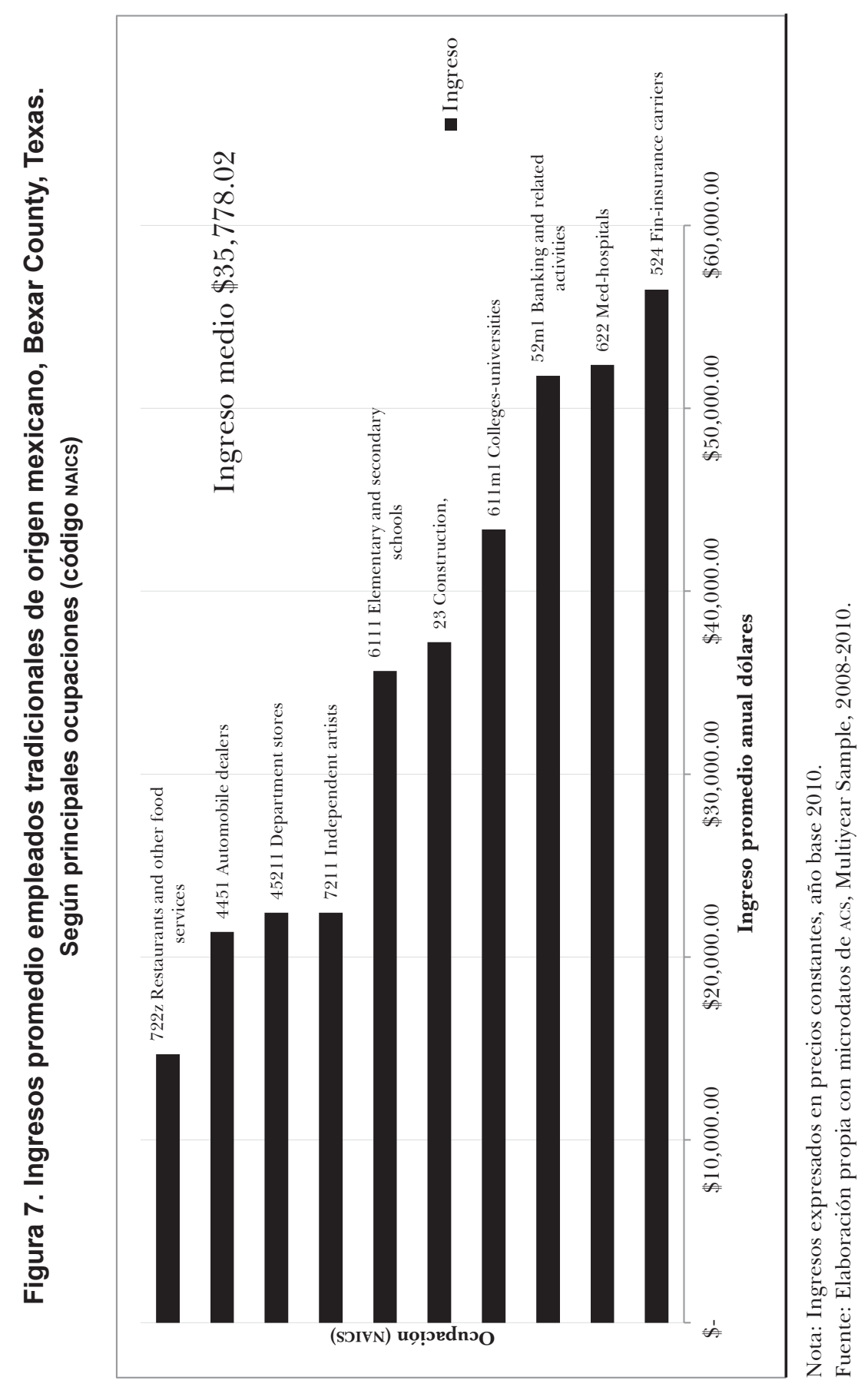


José Luis Manzanares Rivera / Los México-americanos en San Antonio, Texas

\section{Estructura familiar e ingreso}

Por otra parte, se aborda la estructura y la estabilidad del entorno familiar, en particular el estatus marital. Autores como Reimers (2006), señalan que la estructura familiar es un factor determinante del estatus económico entre la población de origen mexicano que vive en Estados Unidos; su influencia en el nivel de ingreso se hace evidente al observar las percepciones de una generación a otra.

Así, una estructura familiar de segunda generación (en la que la persona es nacida en Estados Unidos pero los padres nacieron en México) y tercera generación (individuos nacidos en Estados Unidos y ambos padres también) percibe en promedio ingresos significativamente más elevados que la primera generación (nacidos fuera de Estados Unidos); este hecho es importante porque San Antonio, al ser una ciudad considerada como de migración tradicional, cuenta con una proporción de familias de origen mexicano en segunda y tercera generación más elevada que a nivel nacional, lo que implica, según estudios previos, que las oportunidades frente al mercado laboral sean más favorables en tanto este grupo presente niveles más elevados de educación y dominio del idioma inglés, ${ }^{8}$ en relación con los individuos de reciente arribo.

La evidencia censal histórica muestra que la población de origen mexicano que reside en Estados Unidos presenta una estructura familiar tradicional (es decir, es una pareja constituida por un hombre y una mujer que se encuentran casados) en mayor proporción que otros grupos poblacionales (población blanca o afroamericana) (Landale, Oropesa y Bradatan, 2006). Sin embargo, los datos analizados en la encuesta americana de comunidades en el periodo 2008-2010, indican que la comunidad de origen mexicano en Texas ha experimentado cambios drásticos en estos patrones tradicionales, y si bien todavía las tasas de divorcio en condados como Bexar son menores que a nivel estatal (10.5\% para el primer caso contra $11.7 \%$ ), la diferencia es marginal.

Este cambio de tendencia entre las familias no es exclusivo de las familias de origen mexicano y ha sido ampliamente documentado en la literatura en las últimas dos décadas por Popenoe (1993), sin embargo, tiene

${ }^{8}$ Ambos determinantes principales de la posición en el mercado laboral y las percepciones. 
implicaciones importantes para las familias de origen mexicano porque la inestabilidad familiar está asociada con resultados negativos en el mercado laboral, como el nivel de ingreso y el desempleo. De hecho, según datos de la ACs (2012), los ingresos de los divorciados no sólo son menores, sino que se observan tasas más elevadas de desempleo. En la figura 8 se muestra el comportamiento de los ingresos personales promedio reales para 2010, según el estatus marital para la población en el área de San Antonio y el resto del estado.

Se observa que los ingresos personales son menores para aquellas personas cuya situación familiar es inestable; así, aquellos que están separados en el área de San Antonio perciben un ingreso personal inferior hasta en una tercera parte que sus contrapartes que se encuentran casados (19 540 dólares frente a 29725 dólares, respectivamente). Es posible también verificar que la población de origen mexicano que vive en San Antonio percibe ingresos superiores que aquellos que se localizan fuera de esta

Figura 8. Ingreso personal promedio según estatus marital y lugar de residencia

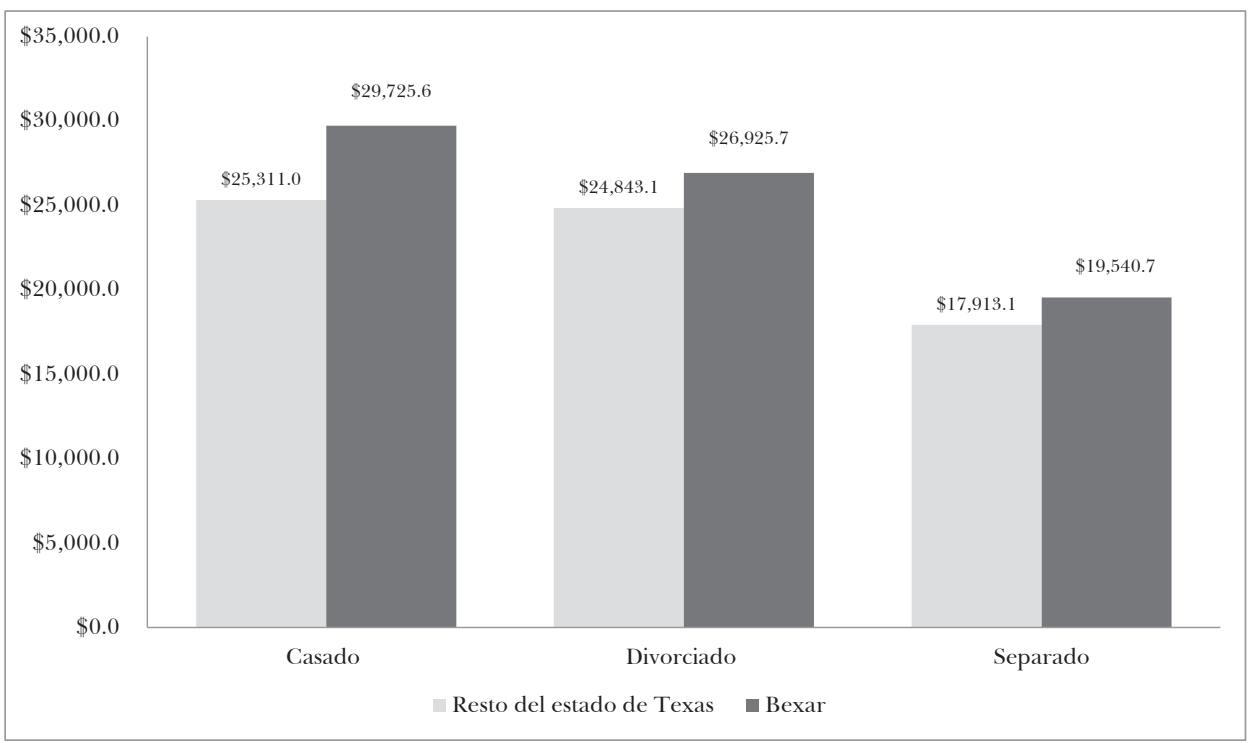

Nota: Ingresos expresados en dólares constantes, año base 2010.

Fuente: Elaboración propia con microdatos de Acs, Multiyear Sample, 2008-2010. 
José Luis Manzanares Rivera / Los México-americanos en San Antonio, Texas

área para cada estatus marital, con ingresos superiores para los que están casados; esto sugiere que la estabilidad marital tiene implicaciones para los resultados en el mercado laboral.

\section{Análisis inferencial}

\section{Aspectos metodológicos}

El análisis se realiza usando microdatos de uso público (Public Use Microdata [PUM]), de la encuesta americana de comunidades (ACS, 2012). La ACS es una encuesta que contiene estimados en periodos intercensales en dos versiones: multianual y anual. Este trabajo usa la versión multianual de tres años, ya que permite un nivel de desagregación mayor que la versión anual. Mientras la versión anual contiene estimados para áreas geográficas a partir de 65000 habitantes, la versión multianual de tres años contiene estimados para áreas geográficas a partir de 20000 habitantes, permitiendo así analizar detalladamente las características al interior de un condado, como se hace en el presente estudio.

La Acs es realizada por la oficina del censo estadounidense y aborda los principales temas socioeconómicos, de tal forma que contiene información de variables como: tipo de empleo, educación, ingreso personal y familiar, entre otras. Consta de dos tipos de registros, uno para hogares y el otro a nivel individual, para este último caso la muestra para el estado de Texas contiene 1174125 observaciones, lo que corresponde a $5 \%$ de la población en el estado y que una vez expandida permite estimaciones estadísticamente representativas para la población en áreas pequeñas como los condados, mismas que están referenciadas geográficamente mediante una variable de enlace, Public Use Micro Data Areas (PumAs); esta variable hace referencia a áreas con una población de 100000 habitantes o más, por lo que resulta de la composición de census tracts adyacentes. Esta característica de la encuesta en cuanto a la desagregación, la hace un instrumento de utilidad para este trabajo, ya que permite aplicar técnicas de análisis espacial para entender los efectos de la localización de la población de origen mexicano en el contexto sub-estatal. 


\section{Análisis de regresión logística}

Con el objetivo de aproximar el estatus de los individuos como emprendedores en esta sección se aplica la técnica estadística de regresión logística para evaluar la probabilidad de que un individuo se encuentre empleado en una empresa propia registrada formalmente; esta variable refleja el estatus de emprendedor de la persona, la variable es dicótoma y toma los valores 0: no emprendedor, 1: emprendedor.

El modelo considera tres variables independientes seleccionadas con base en la literatura sobre capital social en un contexto de migración. Estas variables, según se ha argumentado en estudios previos, son relevantes para explicar la inserción de los individuos en el mercado laboral; el modelo presentado busca extender este análisis previo hacia un entorno de emprendimiento. Las variables independientes son: origen de la persona, es una variable dicótoma que toma los valores 0: no es de origen mexicano, 1: de origen mexicano. El grado de dominio del idioma inglés: variable categórica que toma cuatro valores: 1: muy bien, 2: bien, 3: no bien, y 4: no lo habla.

La tercera variable es el estatus marital, que es una variable categórica que toma seis valores 1: casado, esposa presente; 2: casado, esposa ausente; 3: viudo; 4: divorciado; 5: separado; y 6: nunca casado. La estimación del modelo se realiza en dos escenarios con la finalidad de contrastar la hipótesis sobre la existencia de lazos sociales que favorecen a la población de origen mexicano en San Antonio, Texas, en cuanto a su propensión hacia el emprendimiento.

El primer escenario considera una muestra que contiene la población del estado de Texas, y el segundo, únicamente la población en el área de San Antonio, Condado de Bexar, aislando de esta manera el efecto de cada variable independiente en el resultado.

El modelo logístico que se estimará en su forma teórica es:

$$
P\left(\text { emprendedor }=1 \mid X_{1}, X_{2} \ldots X_{\mathrm{k}}\right)=\frac{1}{\left(1+e^{-\left(\alpha+\Sigma \beta_{i} X_{i}\right)}\right.}
$$

El modelo permite determinar la probabilidad de que un individuo que vive en el estado de Texas (modelo 2) o en San Antonio (modelo 1) se emplee por cuenta propia en función de las variables independientes ya señaladas. 
El modelo en su forma explícita es:

$$
P\left(\text { emprendedor }=1 \mid X_{1}, X_{2} \ldots X_{\mathrm{k}}\right)=\frac{1}{\left(1+e^{-\left(\alpha+\beta_{1} \text { origen }+\beta_{2} m s p+\beta_{3} \text { eng }\right)}\right.}
$$

De esta manera, se espera una relación inversa para la variable origen de la especificación estatal (modelo 2) y una relación positiva entre esta variable y el empleo en empresas propias para el caso de San Antonio (modelo 1).

En cuanto a la variable estatus marital (msp), se espera una relación positiva con la categoría casado y una menor influencia a medida que los lazos de unión son menores, como las categorías divorciado o separado. Finalmente, la variable que indica el grado de dominio del idioma inglés se espera que exhiba una importancia relativa menor en San Antonio que en el resto del estado.

Los resultados de la estimación se presentan en el cuadro 2.

Cuadro 2. Modelo logístico. Empleo por cuenta propia

\begin{tabular}{|ccccccc|}
\hline \multirow{2}{*}{ Emprendedor } & \multicolumn{3}{c}{ Modelo 1 } & \multicolumn{5}{c|}{ Modelo 2 } \\
\cline { 2 - 7 } & Ratio & $z$ & $P>z$ & $\begin{array}{c}\text { Odds } \\
\text { Ratio }\end{array}$ & $z$ & $P>z$ \\
\hline Origen & 0.59 & -4.3 & 0 & 0.43 & -20.48 & 0.00 \\
\hline Estatus marital & & & & & & \\
\hline 2 & 0.79 & -0.8 & 0.4 & 0.62 & -4.58 & 0.00 \\
3 & 0.81 & -0.5 & 0.6 & 0.76 & -1.97 & 0.05 \\
4 & 0.41 & -3.5 & 0 & 0.58 & -6.91 & 0.00 \\
5 & 0.32 & -2.3 & 0 & 0.54 & -4.73 & 0.00 \\
6 & 0.43 & -4.7 & 0 & 0.26 & -19.6 & 0.00 \\
\hline Dominio del idioma inglés & & & & \\
\hline 2 & 1.13 & 0.8 & 0.4 & 1.08 & 1.51 & 0.13 \\
3 & 1.77 & 3.2 & 0 & 0.84 & -2.89 & 0.00 \\
4 & 0.57 & -1.2 & 0.2 & 0.53 & -5.7 & 0.00 \\
\hline
\end{tabular}

Fuente: Elaboración propia con datos de U. S. Census Bureau, ACS Multiyear Sample, 2008-2010 (2012). 
Los resultados permiten corroborar la hipótesis sobre la importancia del origen mexicano como determinante para el fenómeno del emprendimiento en Texas, ya que tanto en el modelo 1 como en el modelo 2 la variable origen es estadísticamente significativa. En el contexto estatal aquellas personas que son de origen mexicano ${ }^{9}$ tienen una menor probabilidad de estar empleados en una empresa propia registrada formalmente; de hecho, la probabilidad de ser emprendedor disminuye marcadamente, hasta en $57.2 \%$, para este grupo poblacional, frente a las personas de otro origen.

Por otro lado, al considerar únicamente la población de origen mexicano que vive en el área de San Antonio (modelo 1), observamos que la probabilidad de estar empleado en una empresa propia es superior en $15.7 \%$ respecto de aquellos que siendo de origen mexicano viven fuera del área de San Antonio. Este resultado da soporte a la hipótesis sobre la importancia de los lazos sociales entre la comunidad mexicana en San Antonio.

El dominio del idioma inglés es un determinante fundamental del tipo de empleo así como del nivel de ingreso percibido; respecto de esta variable, las estimaciones para el modelo a nivel estatal muestran que a medida que el dominio del idioma inglés es menor, se tienen menores probabilidades de ser un emprendedor; inicialmente hay una reducción de $16 \%$ entre la población que no lo habla muy bien respecto de los que dominan el inglés, pero la reducción es todavía más pronunciada (de 46.5\%) para aquellos que en definitiva no hablan inglés. Este resultado es un indicador de la importancia del manejo del idioma como herramienta de capital humano y concuerda con estudios empíricos realizados en otro contexto por Chiswick (2008).

El caso de San Antonio es interesante en este sentido ya que la herencia cultural, así como los flujos continuos de población con origen mexicano han influido en los mecanismos de comunicación. Así, al evaluar el efecto de la variable del idioma inglés sobre la condición de emprendimiento para el modelo 1, observamos que en San Antonio, el hecho de no hablar bien inglés se asocia con un incremento de las posibilidades de incursionar en una empresa propia. La figura 9 muestra el comportamiento

\footnotetext{
${ }^{9}$ Tienen ancestro mexicano.
} 
Figura 9. Tendencia probabilidades estimadas. Categoría emprendedor según habilidad en el idioma inglés

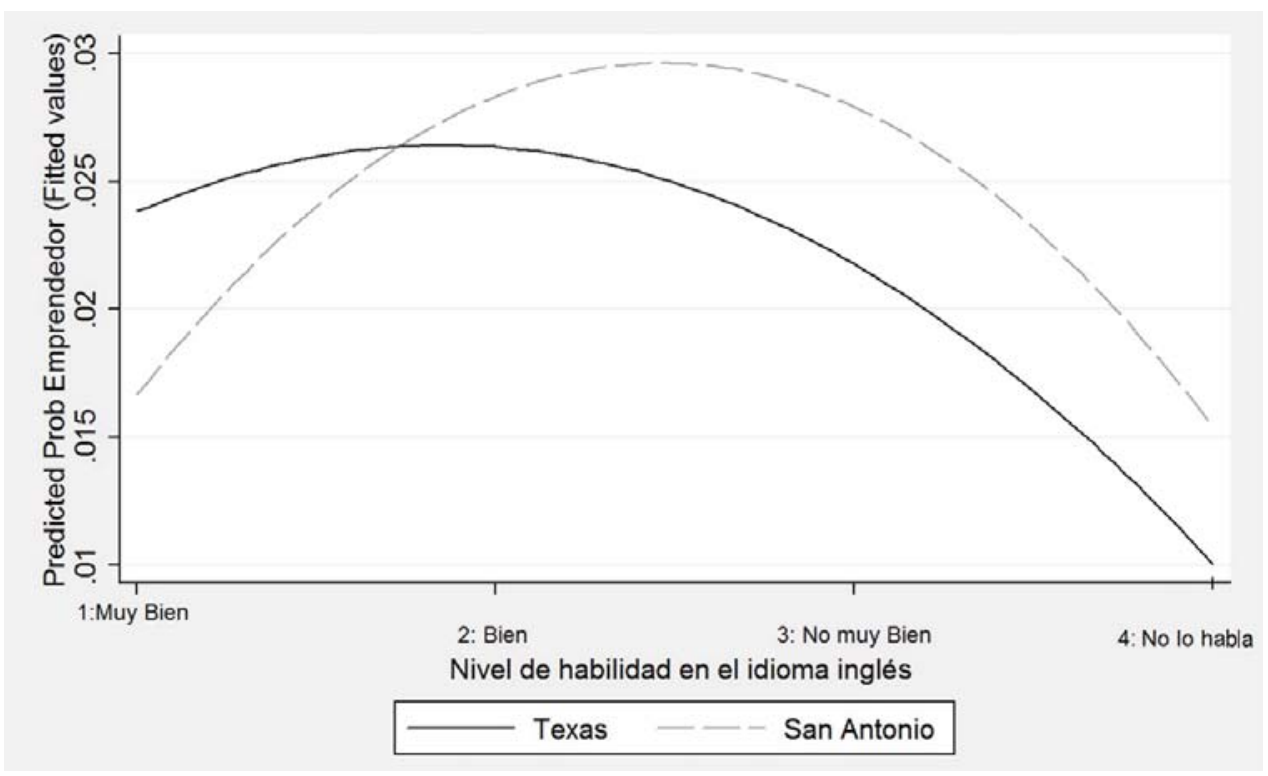

Fuente: Estimaciones propias con base en microdatos de Acs, 2008-2010.

de las probabilidades estimadas para la categoría emprendedor según la habilidad en el idioma inglés para la población del estado de Texas y la población del área de San Antonio.

En el caso del estado, las probabilidades de pertenecer a la categoría emprendedor son inicialmente más elevadas que las observadas para los individuos que viven en San Antonio; sin embargo, se observa que a medida que el dominio del idioma inglés es menor, las probabilidades de ser emprendedor descienden rápidamente y permanecen por debajo de aquellas para su contraparte que viven en San Antonio, hasta niveles cercanos a cero en el caso de que el individuo no hable inglés.

Este comportamiento contrasta radicalmente con lo ocurrido en San Antonio, ya que para este último caso la probabilidad de ser emprendor se eleva a medida que el dominio del idioma inglés es menor. En ambos casos los individuos que no lo hablan en su totalidad tienen probabilidades prácticamente nulas de estar en la categoría de emprendedor. 
Por otro lado, los resultados en torno a la variable que refleja la situación marital indican que aquellas personas que tienen menos lazos familiares (ej. divorciados, separados o nunca casados), exhiben una probabilidad menor a laborar en empresas propias, respecto de los que están casados. ${ }^{10}$ Así una persona que ha experimentado una separación y que vive en el área de San Antonio, tendrá una probabilidad inferior en 68\%, de encontrarse empleado en su propia empresa respecto a aquellos que permanecen casados.

$\mathrm{Al}$ observar el coeficiente de la categoría 5 para el modelo 2 se verifica que el hecho de estar separado reduce la probabilidad de pertenecer a la categoría de emprendedor en $46 \%$ (1-.54), de modo que en ambos casos (San Antonio y contexto estatal), la inestabilidad de los lazos familiares expresados por la relación de pareja afecta negativamente el entorno del emprendimiento.

\section{Conclusiones}

El presente trabajo ha investigado el tema del autoempleo formal y actividades profesionales por cuenta propia entre la población de origen mexicano en el área de San Antonio, Texas, en un esfuerzo por contribuir al estudio del mercado laboral en ciudades que son consideradas como de migración tradicional o Gateway cities. La hipótesis del trabajo planteó que variables como el dominio del idioma inglés o el origen mexicano de la persona, en ciudades de migración tradicional como San Antonio, Texas, no necesariamente implican barreras significativas para la inserción de la población de origen mexicano en el mercado laboral formal dentro de la categoría de autoempleo. El argumento implícito del trabajo se basa en que la población de origen mexicano que vive en Estados Unidos es muy diversa, no obstante es tratada en la literatura como un solo grupo que relaciona un estereotipo entre pobreza y migración indocumentada, salvo notables casos, tales como el trabajo de Valdez (2006).

Sin embargo, como se documentó a lo largo del trabajo, las diferencias al interior de la población de origen mexicano en tanto su inserción

${ }^{10}$ La tendencia no presenta diferencia importante entre el contexto estatal y el condado de Bexar (San Antonio). 
en el mercado laboral, se hacen evidentes al considerar factores como la asimilación que ocurre de una generación a otra, las diferencias de capital humano como la educación y el grado de dominio del idioma inglés.

Los resultados del análisis inferencial mediante el modelo logístico permiten destacar tres elementos: primero, en San Antonio, Texas, las personas de origen mexicano tienen una probabilidad superior a la observada en el resto del estado de Texas de encontrarse empleados en una empresa propia formalmente registrada, este elemento permite reforzar la hipótesis planteada sobre la existencia de lazos sociales propios de una ciudad en la categoría Gateway.

En segundo lugar, se mostró que el dominio del idioma inglés es un determinante fundamental del tipo de empleo así como del nivel de ingreso percibido. Respecto de esta variable, las estimaciones para el modelo a nivel estatal muestran que a medida que el dominio del idioma inglés es menor, se reducen las probabilidades de pertenencia a la categoría autoempleo, la reducción estimada es del orden de $46.5 \%$ para aquellos que en definitiva no hablan inglés. Este resultado es un indicador de la importancia del manejo del idioma como herramienta de capital humano y concuerda con estudios empíricos realizados en otro contexto (Chiswick, 2008).

Sin embargo, el caso de San Antonio es interesante al evaluar el efecto de la variable idioma inglés sobre la condición de emprendimiento ya que se halló que el hecho de no hablar bien inglés se asocia con un incremento de las posibilidades de incursionar en una empresa propia, lo que al parecer muestra que la herencia cultural así como los flujos continuos de población con origen mexicano han influido en los mecanismos generando lazos sociales que inhiben la necesidad de dominar el idioma inglés.

En tercer lugar, los resultados en torno a la variable que refleja la situación marital indican que aquellas personas que tienen menos lazos familiares (ej. divorciados, separados o nunca casados), exhiben una probabilidad menor a laborar en empresas propias, respecto de los que están casados.

Este resultado sugiere que la inestabilidad de los lazos familiares expresados por la relación de pareja afectan negativamente el entorno del emprendimiento; no obstante, se encontró que este efecto adverso es claramente más pronunciado para los individuos residentes en San Antonio.

Los resultados del artículo permiten destacar la necesidad de atender un aspecto fuera del estereotipo de la población de origen mexicano y 
permiten generar nuevas preguntas sobre el comportamiento del autoempleo formal entre los mexicanos en otras ciudades con presencia tradicional de población de origen mexicano, como son las ciudades de los estados fronterizos de California, Nuevo México o Arizona.

\section{Bibliografía}

Arreola, D. (1987). The Mexican American cultural capital. Geographical Review, $77(1), 17-34$.

Barros, M. (2007). El matrimonio y las pequeñas empresas comerciales. El caso de los salvadoreños y mexicanos en Los Ángeles. Revista Mexicana de Sociología, 69(1), pp. 109-138.

Becker, G. S. (1975). Human capital: A theoretical and empirical analysis, with special reference to education ( $2^{\mathrm{da}} \mathrm{ed}$.). Cambridge: NBER.

Chiswick, B. R. (2008). The economics of language: An introduction and overview. (Documento de debate iza No. 3568). Bonn: Institute for the Study of Labor, junio.

Chiswick, B. R. (1990). Speaking, reading and earnings among low-skilled immigrants. Journal of Labor Economics, 9(2), 149-70.

Cuesta, M., Verduras, C. y Carcedo, J. (2008). Commuting times: Is there any penalty for immigrants? Urban Studies Journal Limited, 47(8), 1663-1686.

Donato, K. M. y Blake, S. (2012). Shifts in the employment outcomes among Mexican migrants to the United States, 1976-2009. Research in Social Stratification and Mobility, 30(1), 63-77.

Donato, K. M. y Massey, D. S. (1993). Effect of the Immigration Reform and Control Act on the wages of Mexican migrants. Social Science Quarterly, 74(3), 523-41.

Duncan, B., Hotz, V. J. y Trejo, S. (2006). Hispanics in the U.S. Labor Market. En M. Tienda y M. Faith (Eds.), Hispanics and the Future of America (pp. 228-290). Washington, DC: National Academies Press.

Fairlie, R. W. y Woodruff, C. (2004). Mexican entrepreneurship: A comparison of self-employment in Mexico and the United States. En G. J. Borjas, (Ed.), Mexican Immigration to the United States (pp. 123-158). Estados Unidos: University of Chicago Press.

Georgarakos, D. y Tatsiramos, K. (2009). Entrepreneurship and survival dynamics of immigrants to the U.S. and their descendants. Labour Economics, 16(2), 161170 .

Granovetter, M. (1973). The strength of weak ties, American Journal of Sociology, 78(6), 1360-1380. 
Granovetter, M. (2005). The impact of social structure on economic outcomes. The Journal of Economic Perspectives, 19(1), 33-50.

Grogger, J. y Trejo, S. (2002). Falling behind or moving up? The Intergenerational Progress of Mexican Americans. Sacramento: Public Policy Institute of California.

Landale, N., Oropesa, S. y Bradatan, C. (2006). Hispanic families in the United States: Family structure and process in an era of family change. En M. Tienda y M. Faith (Eds.), Hispanics and the Future of America (100-137). Washington, DC: National Academies Press.

Light, I., Sabagh, G., Bozorgmehr, M. y Der-Martirosian, C. (1994). Beyond the ethnic enclave economy. Social Problems, 41(1), 65-80.

Light, I. H. (1972). Ethnic Enterprise in America: Business and Welfare among Chinese, Japanese and Blacks. Berkeley: University of California Press.

Lofstrom, M. (2002). Labor market assimilation and the self-employment decision of immigrant entrepreneurs. Journal of Population Economics, 15(1), 83-114.

Mahuteau, S. y Junankar, P. (2007). Do Migrants Succeed in the Australian Labour Market? Furher Evidence on Job Quality. (MPRA Paper No. 8703).

Mincer, J. A. (1974). Introduction to schooling, experience, and earnings. En J. A. Mincer (Comp.), Schooling, Experience, and Earnings (pp. 1-4). Nueva York: NBER Columbia University Press.

Massey, D. S., Rugh, J. S. y Pren, K. A. (2010). The Geography of Undocumented Mexican Migration. California: University of California Press.

Popenoe, D. (1993). American family decline, 1960-1990: A review and appraisal. Journal of Marriage and the Family, 55(3), 527-42.

Portes, A. (1981). Modes of structural incorporation and present theories of labor immigration. En M. Kritz, C. B. Keeley y S. Tomasi (Eds.), Global Trends in Migration (pp. 279-297). Nueva York: Center for Migration Studies.

Preston, V. y Mclafferty, S. (1999). Spatial mismatch research in the 1990s: Progress and potential. Papers in Regional Science, 78(4), 387-402.

Public Use Microdata Sample (Pums). (2011). Microdatos de uso público estado de Texas. ACS. Recuperado de: <http://factfinder2.census.gov/faces/tableservices/jsf/pages/productview.xhtml?pid=ACS_pums_csv_2010\&prodType $=$ document $>$

Raijman, R. (2001). Determinants of entrepreneurial intentions: Mexican immigrants in Chicago. Journal of Socio-Economics, 30(5), 393-411.

Raijman, R., y Tienda, M. (1999). Immigrants socio-economic progress post1965: Forging mobility or survival? En C. Hirschman, P. Kasinitz y J. DeWind (Eds.), The Handbook of International Migration (pp. 239-256). Nueva York: Russell Sage Foundation.

Ramírez, H. y Hondagneu-Sotelo, P. (2009). Mexican immigrant gardeners: Entrepreneurs or exploited workers? Social Problems, 56(1), 70-88. 
Reimers, C. (2006). Economic well-being. En M. Tienda y M. Faith (Eds.), Hispanics and the Future of America (pp. 291-361). Washington, DC: National Academies Press.

Robles, B. J. y Cordero-Guzmán, H. (2007). Latino self-employment and entrepreneurship in the United States: An overview of the literature and data sources. Annals of the American Academy of Political and Social Science (Vol. 613, pp. 18-31). Advancing Research on Minority Entrepreneurship.

Rumbaut, R. (2006). The making of a people. En M. Tienda y M. Faith, (Eds.), Hispanics and the Future of America (pp. 16-65). Washington, DC: National Academies Press.

Toussaint-Comeau, M. (2008). Do ethnic enclaves and networks promote immigrant self-employment? Economic Perspectives, 32(4), 30-50.

U.S. Census Bureau.(2010). Recuperado de: <http://www.census.gov/2010census/ popmap/ipmtext.php?fl=48>

U. S. Census Bureau. (Febrero, 2012). Recuperado de: <http://quickfacts.census. gov/qfd/states/06/06037.html>

U. S. Census Bureau American Community Survey (ACS) (Febrero, 2012). Recuperado de: < http://www.census.gov/acs/www/Downloads/survey_methodology/acs_design_methodology_ch06.pdf>

Valdez, Z. (2006). Segmented assimilation among Mexicans in the Southwest. The Sociological Quarterly, 47(3), 397-424.

Xue, L. (2008). Social Capital and Employment Entry of Recent Immigrants to Canada. (Research and evaluation paper). Ottawa: Citizen and Immigration Canada. 
